\title{
Oration \\ Dr. F.A. Wickramasinghe Oration 2015 Beyond borders: enhancing public health security at points of entry to Sri Lanka
}

\author{
Vindya Kumarapeli $1^{*}$
}

We live in a unique and unprecedented era in human history. We are more divided as humanity yet more connected, laced and knitted than ever before. Infectious disease pandemics, radio-nuclear or toxic industrial accidents, conflicts, and natural disasters have emerged as threats to global public health security during the past few decades.

\section{Global public health security}

The World Health Organization (WHO) defines global public health security in its 2007 World Health Report as the "activities required, both proactive and reactive, to minimize vulnerability to acute public health events that endanger the collective health of populations living across geographical regions and international boundaries" (1). There is evidence in the literature for instances where lack of global public health security has manifested in different ways in the past.

Inadequate investment in public health is best illustrated by the emergence and re-emergence of vectorborne diseases such as African trypanosomiasis, dengue haemorrhagic fever and malaria in the 1970s. This mostly resulted from a false sense of security due to the absence of outbreaks of these infectious diseases, causing reduced vigilance and relaxing of adherence to effective prevention programmes. The outbreak of Marburg haemorrhagic fever, which occurred after the 27-year civil war in Angola is an example for public health consequences of conflicts. The Cholera epidemic in the Congo, which occurred when 500,000 - 800,000 people from Rwanda crossed its borders to seek refuge reflects the same (1). The variant Creutzfeldt-Jakob disease (vCJD) or the human bovine spongiform encephalopathy (BSE) or human form of "mad cow disease" outbreak in 1995 in UK due to consumption of meat contaminated with brain matter of infected cows, is an example for threats related to animal husbandry and food processing. Similarly the encephalitis due to Nipah virus outbreak in 1998 in Malaysia, with a case fatality rate of up to $75 \%$, was associated with direct contact with sick or dying pigs or fresh pig products (1).

Lack of global public health security has an impact on economic and political stability, trade and tourism. Complex dynamics of an ever increasing international migration flow, in the present day emphasize the need to strengthen the points of entry (POE) (airports, seaports, ground crossings) to prevent the international spread of infectious diseases, one of the major threats to the global health security. Increased international air travel, with 1 billion people crossing international borders each year, has caused spread of infectious disease across the globe faster and farther. The speed of spread of disease through aircrafts is best illustrated by the outbreaks of SARS in 2003 (2) and Influenza A in 2009,(3); similarly round 50,000 merchant ships, manned by over one million seafarers, which carry cargo across 150 countries could spread infectious diseases through sea ports.

1. Director (Training), Education, Training and Research Unit, Ministry of Health, Nutrition and Indigenous Medicine, Sri Lanka.
*Correspondence: vindyalk@yahoo.com DOI: 10.4038/jccpsl.v22i1.8085 


\section{International health quarantine}

International health quarantine first appeared in the $14^{\text {th }}$ Century. In Europe, the earliest industrial and commercial cities emerged in the North Italy and along the Mediterranean. With development of foreign trade, increasing naval transportation and newly-explored shipping routes, infectious diseases like plague, cholera swept through Europe, and spread out. Europe experienced the most deadly infectious disease outbreak in the history when the 'Black Death', the pandemic of bubonic plague in 1347, killed a third of the human population (4). To prevent the spread of these diseases, some countries adopted quarantine of ships which came from epidemic areas. The term "quarantine" dates back to the $14^{\text {th }}$ century when people arriving from plague-infected areas to the port of Ragusa, Italy were isolated. This period of isolation was set at 40 days and the word quarantine derived from the word "quaranta" the Italian term for "forty". In 1710, United Kingdom established the quarantine organization, and countries across Eurasia followed the example of UK (5).

\section{International Health Regulations}

By the end of the $19^{\text {th }}$ century, many international conferences on disease control had been held, focusing on the containment of epidemics within their regions of origin. The first International Sanitary Convention of 1892, became the International Sanitary Regulations. Through many revisions, in 1951, WHO adopted the existing conventions at the time as the International Sanitary Regulations, which became binding on WHO member states. However, international sanitary regulations of 1951 highlighted that measures at POE alone could prevent the spread of infectious diseases across international borders. It intended to monitor and control only six serious infectious diseases: The Sanitary Regulations (1951) were renamed as the International Health Regulations (IHR) in 1969 (5). However, over time, compliance with the regulations diminished, and the global surveillance system under the IHR (1969) gradually faded, diminished in relevance and effectiveness (5). With the threat of emerging and re-emerging infectious diseases such as Ebola virus in Congo and the epidemic of plague in India in the 1990's, the inadequacy of mechanisms available for controlling the cross-border outbreaks were recognised, resulting in a resolution at the World Health Assembly in 1995. This resolution was to revise the IHR (1969), to help in global governance of disease reporting and responses. However, there was only little progress until the emergence of the SARS virus in 2003, which lead to a revised IHR to be adopted by the World Health Assembly in 2005, which came into force in 2007 (6).

The IHR (2005) has shifted the focus of infectious disease in three ways: (a) not limited to any specific diseases, and covers all public health emergencies (b) replaced the historical lists of notifiable diseases with an algorithm (c) 'control at boarders' is supplemented by 'containment at the source', and use 'adapted response' based on real time epidemiological evidence rather than 'pre-determined' measures (6).

The goal of the IHR (2005) is the global public health security and to prevent the spread of diseases and events across international borders. They are a set of legally binding regulations, for the WHO member states and provides a global framework agreed upon by the member states, for the collective international management of epidemics and other public health emergencies while minimizing disruption to travel, trade and economies, and at the same time respecting individual human rights (6). Countries have agreed to share information promptly and to develop and sustain the core capacities needed. So, essentially, time 
tested virtues of human conditions assume legal and scientific dimensions to ensure human protection. This commitment laid the foundation for a global disease detection and response network, capable of containing emerging disease threats. The international response required today is not only to the known, but also to the unknown diseases that may arise from acute environmental or climatic changes and from industrial pollution and accidents that may put millions of people at risk in several countries.

The IHR (2005) identifies several public health hazards: (a) biological (infectious, zoonotic, food born), (b) chemical (c) radio-nuclear material which may cause an international public health emergency. They can be manifested as imported human cases, infected or contaminated vectors or contaminated goods. The implementation of IHR (2005) requires mobilization of national resources; for strengthening the national capacity for early detection of unusual diseases or events by effective national surveillance and for response (investigation, control measures) at all levels (local, regional, and national) (6).

\section{Public health events that spread through points of entry in the recent past}

\section{Biological (infectious, zoonotic, food born) events}

There are numerous examples where infectious diseases and events have spread across the globe causing great adverse health, economic and social consequences. In the past centuries, outbreaks of yellow fever were reported in the North America (Charleston, New Orleans, New York, Philadelphia etc) and Europe (England, France, Ireland, Italy, Portugal and Spain). Although the disease has never been reported in Asia, the region is always at risk, due to presence of the conditions required for transmission. Therefore travellers, particularly those arriving to Asia from Africa or Latin America are required to have a certificate of yellow fever vaccination (1).

There was no better eye opener to the world than the Plague outbreak in India in 1994 of the risk of re-emergence of infectious diseases. The outbreak occurred in five states, resulting in almost 700 suspected cases and 56 deaths. The international media attention given resulted in devastating economic consequences for India, several countries over-reacted exceeding the measures in IHR (1969) and imposed unnecessary travel and trade restrictions. Consequently, India had lost 1.7 billion US dollars in trade and travel (1).

The outbreak of SARS in 2003 caused 8098 cases and 774 deaths in 26 countries and showed the world how quickly a new disease can spread along the routes of international air travel. Spread through Aircrafts covers a long-range geographically; infectious diseases are mostly in latency and patients are difficult to be discovered and controlled; sources of travellers are various, therefore differences in languages, cultures, lifestyles and religious believes have certain effects on the spread of diseases (2).

Ebola virus disease (EVD), and Marburg virus disease (MVD), are among the most virulent pathogens known to infect humans and require containment at their source, due to their acute nature and the resultant fatality. Marburg virus disease (MVD), was first identified in 1967 during epidemics in Marburg, Frankfurt in Germany and Belgrade, from imported infected monkeys from Uganda. Outbreaks were later reported in Congo from 1998-2000 and in Angola in 2005. The first Ebola virus disease (EVD) outbreaks occurred in 1976 in remote villages in Central Africa (1). The current outbreak in West Africa, first reported in March 2014, is the largest and most complex outbreak since the Ebola virus was first 
discovered. It has also spread between countries starting in Guinea then spreading across land borders to Sierra Leone and Liberia, by air (1 traveller) to Nigeria and USA (1 traveller), and by land to Senegal (1 traveller) and Mali (2 travellers) $(7,8)$.

Infectious disease outbreaks can be accidental or deliberate. An activity related to laboratory research has the potential for outbreaks due to accidental release of infectious agents as a result of breaches in biosafety measures. However the Anthrax attacks in the United States in 2001, malicious releases of dangerous pathogens, was a form of bioterrorism that reminded the world of the importance of international health security. Similarly after eradication of smallpox was certified, allegations have been made that some countries and terrorist groups are storing smallpox virus, and its potential as a bioterrorist threat is causing major concerns in many industrialized countries (1).

Avian influenza, variant Creutzfeldt-Jakob disease (human form of mad cow disease) and the Nipah virus infection are some of the newly emerging zoonosis that threatens the public health security. Most avian influenza viruses (bird Flu) do not infect humans; however A (H5N1) and A (H7N9), have caused serious infections in humans. Outbreaks of avian influenza in poultry raise global public health concerns due to their impact on local and global economies and international trade, the potential to cause serious disease in people, and their pandemic potential. The A (H5N1) virus subtype, a highly pathogenic avian influenza, first infected humans in 1997 during a poultry outbreak in Hong Kong. It re-emerged in 2003 and 2004, and later spread from Asia to Europe and Africa and has become entrenched in poultry in some countries. A (H7N9) virus subtype, a low pathogenic avian influenza virus, has infected 3 humans in March 2013 in China, but no cases outside China have been reported. In 2009 the United States experienced a pandemic of $\mathrm{A} / \mathrm{H} 1 \mathrm{~N} 1$ which spread to the US from an outbreak in Mexico. This spread across the 50 states (3). The estimated loss to the Mexican economy due to influenza was at 0.3 to 0.5 percent of GDP for 2009 and Mexican citizens traveling abroad became subjects of discrimination (1). In a world of constant human migration, the greatest threat to international health security would be an avian influenza pandemic. With the growth of global trade and travel, a localized epidemic can transform into a pandemic rapidly, with little time to prepare a public health response. Influenza pandemics occur when two key factors converge: an influenza virus emerging with the ability to cause sustained humanto-human transmission, and the human population has little or no immunity against the virus. The continuing possibility of pandemics is a major threat to global public health security, The main reasons for this increased risk are the occurrence of these diseases in developing countries where the ability to detect and respond rapidly is limited. The newly emerging diseases in humans are often due to a breach in barrier between humans and animals, permitting microbes that infect animals to cause human infection as well (3).

Contaminated food is an important source of food borne diseases. Although the safety of food has dramatically improved over the last 50 years, foodborne outbreaks from microbial contamination, chemicals and toxins are common in many countries. Trading of contaminated food between countries increases the potential for outbreaks. Cholera remains a global threat to public health security since its spread across the globe in the 19th century, from the Ganges delta in India. Six subsequent pandemics have killed millions of people across the world. The current pandemic started in South Asia in 1961. Cholera is now endemic in many countries. The true burden of cholera is underreported due to limitations in surveillance systems and fear of trade and travel sanctions. Countries neighbouring cholera -affected 
areas are encouraged to strengthen disease surveillance and national preparedness to rapidly detect and respond to outbreaks if it spreads across borders (1).

\section{Chemical and radio-nuclear material related public health events}

We have a dark and sad memory of our neighbour India succumbing to an industrial disaster. The most significant chemical accident recorded in history was the Bhopal disaster in India in 1984, in which over 500,000 people were exposed and more than 3,000 people were killed after a highly toxic vapour (methyl isocyanate) was released at a Union Carbide pesticides factory. The toxic substance spread into and around the areas near the plant (1). Chernobyl disaster, the worst nuclear plant accident in history occurred in 1986 in Ukraine, resulted in the radioactive contamination of the surrounding geographical area, which spread over much of the western USSR and Europe, resulting in the evacuation and resettlement of over 336,000 people. It is the first level 7 event (the maximum classification) on the International Nuclear Event Scale, 400 times more radioactive material released than by the atomic bombing of Hiroshima. Less severe nuclear accidents have been reported in Japan. The more recent event in 2011, at the Fukushima Nuclear Power Station, Japan occurred shortly after the earthquake and tsunami hit Japan (9).

The universal vulnerability for all these hazards indicates the need for a coordinated international response in terms of international public health security. In the age of fast and furious information exchange, what sort of a response do public health emergencies evoke?

\section{Public health emergencies of international concern (PHEIC)}

A PHEIC is an extraordinary event which is determined, to constitute a public health risk to other States through the international spread of disease and to potentially require a coordinated international response (10). The responsibility of determining whether an event is a PHEIC lies with the WHO Director-General and requires the convening of the IHR Emergency Committee Temporary recommendations include health measures to be implemented by the country experiencing the PHEIC, or by other countries, to prevent or reduce the international spread and avoid unnecessary interference with international traffic (10).

Events detected by the national surveillance system, are assessed according to the decision instrument of the WHO. Four diseases are always notifiable irrespective of the number of cases i.e. polio (wild-type polio virus), smallpox, human influenza new subtype, SARS; some are potentially notifiable- cholera, pneumonic plague, yellow fever, VHF (Ebola, Lassa, Marburg), West Nile Fever, or other diseases that are of special national or regional concern, e.g. dengue fever, Rift Valley fever, and meningococcal diseases because they have demonstrated the ability to cause serious public health impact and to spread rapidity internationally. The four criteria given by the WHO need to be fulfilled for the notification: (a) public health impact is serious (b) the event is unusual or unexpected (c) has significant risk of international spread (d) risk of international travel or trade restriction (10).

A PHEIC declaration was first issued in April 2009 when the H1N1 pandemic was in phase 3 (11); the second PHEIC declaration was issued in May 2014 with the resurgence of polio in Syria after its neareradication (12). The wild poliovirus has been exported from 3 countries (Pakistan, Cameroon, and Syria) 
to 3 other countries in central Asia (from Pakistan to Afghanistan), in the Middle East (Syria to Iraq) and in Central Africa (Cameroon to Equatorial Guinea), which were having humanitarian emergencies and other health challenges. On August $8^{\text {th }} 2014$, WHO declared its third PHEIC in response to the outbreak of Ebola in Western Africa (13). The outbreak of Middle East Respiratory Syndrome (MERS-CoV) is an emerging infectious disease. To date, 26 countries have reported cases including few countries in Asia. 186 cases and 36 deaths have been reported in Republic of Korea. Human-to-human transmission has been confirmed especially among close household contacts \& hospital settings, showing potential for a pandemic of zoonotic disease. However this was not declared as a PHEIC as it did not fulfil the required criteria (10).

The inter-connected survival of human race in this complex age of global cohesion and global division, global governance is central for the health and safety of humanity. The IHR can be used as a tool for pandemic preparedness and response within the context of global health governance or for 'governing' the global response to outbreaks. The IHR is the strongest existing tool for global health governance, integrating stakeholders beyond the major state powers into the global disease detection and response. The IHR (2005) expanded the WHO's authority in global health governance and allowed to use external sources of information to identify possible public health emergencies, to make inquiries from national authorities based on unofficial information sources and to state recommendations even in the absence of cooperation or agreement from affected Member States (5).

The H1N1 influenza outbreak in 2009 tested the revised IHR (2005) and demonstrated its shortcomings, such as the dependence on national capacities and additional trade, and travel recommendations. Following its declaration as a PHEIC, there were concerns whether WHO should hold authority to declare a pandemic, given the economic consequences of approximately $\$ 18$ billion for the decision. The move from pandemic alert level 4 to 5 led to immediate economic consequences, particularly for travel and trade-dependent industries. Many national decision makers strongly pressured WHO to consider illness severity in moving past level 5 , fearing that economic impacts of the declaration would be disproportionately greater to the actual disease threat (8).

The third PHEIC due to the outbreak of Ebola in Guinea in December 2013, spread to Liberia and Sierra Leone in March 2014, At least 10,000 people have died from the disease. The CDC estimated that earlier intervention could have prevented the disease's spread, with less than 5,000 people dead (8). There is criticism that there was a delay in declaring a PHEIC by the WHO for the Ebola outbreak that probably enabled it to spread rapidly. The rising number of infections and deaths in Liberia and Sierra Leone, prompted the UN Security Council to issue a landmark resolution on 18 September 2014 establishing the UN Mission for Emergency Ebola Response (UNMEER) (8). The biggest criticism of the current approach is that IHR is heavily focused on formal points of entry and exit, and did not take into account the human mobility aspects and the porous border crossings people take. In addition, emphasis was mostly on health rather than meaningful inter-sectoral and multi-disciplinary coordination. Failure to contain the Ebola outbreak resulted in recognizing the gaps in global governance, in terms of global health security. As a result USA launched its Global Health Security Agenda in 2014 "to accelerate progress toward a world safe and secure from infectious disease threats and to promote global health security as an international security priority" (8). The lesson from Ebola has urged to return to the content of IHR to evaluate how to better prepare countries and the WHO for the next outbreak. This 
raises questions regarding the extent to which the IHR (2005) and the associated powers conferred on WHO can serve as a framework for global governance of disease control. If IHR (2005) were to serve as an effective framework for global governance of disease control, the regulations should be well operationalized in all member countries, which is yet to happen.

\section{Failure in fully operationalizing global governance of disease through IHR (2005)}

It is possible to recognize some key factors that have contributed to the failures of fully operationalizing the concept of global governance of disease through IHR $(2005)(7,8,14)$. (a) For most countries in the world there are many competing priorities, growing non-communicable disease burdens, etc., than chemical and radiological safety efforts, especially in the absence of obvious risks. (b) There was no additional financing, or a standing fund to support countries and the Development partners have often proved as scared by the complex demands of implementing it. (c) The legally binding nature of IHR (2005) does not include an enforcement mechanism for the counties which fail to comply. There is no formal penalty for failure to notify WHO of a potential PHEIC, or for failure to achieve core capacities. WHO has no power to force nations to comply with IHR (2005) obligations. (d) The selfreporting adopted to monitor the implementation of IHR is unreliable and there is no robust mechanism for independent monitoring of its implementation. (e) many low- and middle-income countries do not have the capacities to implement such a framework-core capacities depend on an adequately trained and equipped public health workforce, a strong surveillance and response framework, a functional national public health laboratory network, a strong legal and regulatory foundation, and robust multi-sectoral coordination. As of 2013, only a one fifth of countries had achieved all of the core capacities required and 110 countries requested a 2-year extension, approximately $80 \%$ of the countries have not met their international legal obligations to implement IHR. (f) IHR Monitoring Framework has 20 country-level indicators. It describes only the outcomes that countries should achieve, but does not prescribe how countries should achieve these. There is an unmet need for specific technical assistance, especially for developing capacities for non-infectious hazards. (g) Incorporating surveillance and response at POE, needs lot of inter-sectoral collaboration, and are challenging for most countries $(7,8,14)$.

As a result countries have failed to ensure that WHO has the full capacity for 'governing' and fully operationalizing the global response to outbreaks. It is also in this context that one has to look at how IHR relates to public health security in Sri Lanka.

\section{Public Health Security at the Points of Entry to Sri Lanka}

Sri Lanka's geographical location in the Indian Ocean has historically been of strategic importance for exploration, commerce and cultural exchange. Sri Lanka's points of entry (POE) comprise of two international airports (Katunayake and Mattala) and four sea ports (Colombo, Galle, Hambantota, Trincomalee). Since the end of the conflicts in the north and the east, Sri Lanka has taken a steep development path with the building of new air ports and sea ports, increasing global business investments; and a rapidly growing tourist industry, which are all associated resulting in increased international migration flow.

The routine activities carried out at the POE mainly focus on preventing the introduction of infectious diseases into Sri Lanka. History of port health laws in Sri Lanka dates back to 1897 with 
the establishment of the 'Quarantine and Prevention of Diseases' Act, which stipulates provisions for preventing the introduction of all contagious and infectious diseases into Sri Lanka (15).

In addition there are more unique activities at the POE targeting the national programmes. Sri Lanka has now interrupted malaria transmission and sustained it - resulting in no indigenous malaria cases reported since October 2012 (16). Increased travel to SL from malaria endemic countries in the form of business, tourism, labour or refugees and with the continued presence of the anophiline vectors in most parts of the country make Sri Lanka vulnerable to reintroduction of malaria. Screening using the Rapid Diagnostic Test and prophylaxis for Malaria is carried out at the POE for travellers and returning irregular migrants from Malaria endemic countries. by the Anti-Malaria Campaign in collaboration with the Department of Immigration and when relevant, the International Organization for Migration (IOM) to ensure that travellers as well as returning irregular migrants migrants are Sri Lankan citizens stranded in Malaria endemic countries. However, the large number of inbound labour migrants coming with tourist visa from India, Pakistan, and Bangladesh poses a formidable threat of re-introduction of local transmission. There were instances in the recent past of maritime interceptions or sea rescues of smuggled and trafficked victims - the 'boat people' voyaging the Indian Ocean and making landings in Sri Lanka. They are potential carriers of communicable diseases including malaria. The MERS-CoV is another threat to public health security to Sri Lanka. Given the large number of labour migrants both from the Middle East and South Korea, returning Hajj pilgrims, tourists, resident visa holders and irregular migrants who have visited the Middle East is always a risk of MERS being introduced to Sri Lanka. It is estimated that $10 \%$ of Sri Lanka's population work as international labor migrants, with $93 \%$ of them residing in the Middle East, with the majority departing to Saudi Arabia, which has reported the largest number of MERS-CoV cases (17). The recent evidence for the tendency of the disease spreading within family clusters may be important in the context of the majority of the Sri Lankan work force in the Middle East being employed as house maids (7). In addition Sri Lanka also promotes male labour migration to South Korea. WHO does not advise special screening at POE or any travel or trade restrictions. At present as a part of the preparedness plan, there is a mechanism in place to monitor and follow up returnees form MER-CoV reporting countries particularly South Korea. This operate through the airports, the central Epidemiology Unit and the Medical Officer of Health (MOH) system in the country.

The Directorate for Quarantine was established by the Ministry of Health in 2008 to ensure the implementation of IHR (2005) in the country. Under the stewardship of the Director are the Port Health Medical Officers and Public Health Inspectors operating at the POE, which form the 'front-line' staff. Two national focal points (NFP) were appointed - Director Quarantine and the Chief Epidemiologist for IHR communications with the WHO and all relevant sectors within the country. Sri Lanka has already designated national focal points for preventing and responding to zoonotic infections (under the purview of Director General of Animal Production and Health), foodborne disease (Director Environment and Occupational Health Unit), chemical hazards (Chairman-Central Environment Authority) and radionuclear hazards (Chairman-Atomic Energy Regulatory Council). 


\section{Capacities to implement IHR (2005) in Sri Lanka}

The core capacities are the capacities needed to detect, assess, notify and report and respond to public health events or emergencies of national and international concern. Article 5 and Annex 1a of the IHR (2005) requires member states to identify service and system gaps. An assessment of the public health infrastructure, facilities and core capacities at POE to Sri Lanka to implement IHR (2005) was carried out in 2009 with the financial support from the World Bank and the WHO and an action plan was developed based on the findings. The eight core capacities at the POE needed to detect, assess, notify and respond to a PHEIC were again evaluated in September 2013 by the Directorate for Quarantine with technical support of the IOM using a multi-method approach. The IHR core capacity monitoring framework developed by the WHO (18) was used as the guide. Services related to IHR (2005) core capacities: human resources, infrastructure (general), financial, networking with other agencies (mechanism), and training related to IHR were assessed in component I. The eight core capacity requirements: national legislation and policy, coordination and NFP communications, surveillance, response, preparedness, risk communication, human resource, laboratory capacity were assessed in component II. Results of the gap analysis provided evidence for a paradigm shift from an archaic disease-only model of 'quarantine' to building an innovative strategy for 'border health', encompassing inter-sectoral coordination for public health, that would enable meeting the modern challenges faced by Sri Lanka in the face of changing dynamics of international travel and disease epidemiology (report available at http://srilanka.iom.int).

\section{Gaps in the national capacity for public health security at the POE to Sri Lanka}

A. A suitable legal framework is a mandatory requirement to prevent entry of multiple hazrds to Sri Lanka. The national legislation and policy related to public health security under the authority of the Ministry of Health include the Quarantine and Prevention of Diseases Ordinance (1960)15, Food Act (No. 20 of 1991) (19), Prevention of Mosquito Breeding Act (No.11 of 2007) (20), SARS regulations (2003) (21) and the list of notifiable diseases (2005) (22). The Quarantine and Prevention of Diseases Ordinance is the key legal document in relation to the implementation of IHR (2005) with provisions for preventing the introduction and spread of all contagious and infectious diseases into and outside Sri Lanka. The ordinance primarily addresses 'contagious diseases' and already 'infected persons' and not 'events' or 'threats' as specified in Annex-ii of the IHR (2005). Although the Competent Authority for the ordinance is the Director General of Health Services (DGHS), Director/Quarantine and the Medical Officer/Port Health who are the implementers of the IHR (2005) have not been delegated the power of the DGHS. Roles and responsibilities of the two NFP, international notification and preparedness for a PHEIC are not included. Partnerships and coordination with other agencies having a stake in response in a PHEIC i.e. Department of Animal Production and Health, Atomic Energy Authority, Central Environmental Authority are not stated. In addition, IHR implementation documents: Maritime Declaration of Health, Aircraft General Declaration, Ship Sanitation Certificates are not specified. Full respect of human rights and the guidance provided by the charter of the United Nations and the constitution of the WHO Article 3 are not reflected in this ordinance. Contaminated food is an important source of food borne diseases. In the multi-hazard approach of IHR (2005), ensuring a safe environment for travellers by inspecting eating establishments, flight catering facilities etc at the POE is a compulsory requirement, Food Act No. 26 1980, which was amended in 
1991 has the required provisions. Food and Drug Inspectors (FDI) are responsible for inspecting cargo containing food whereas the PHII are responsible for inspecting food supplied to travellers. Similarly control of vectors and reservoirs in and near POE is required to prevent transport an infectious agent into or out of the country and is partly addressed by the Prevention of Mosquito Breeding Act (2007) which has provisions to prevent and eradicate mosquito breeding sites in and near a POE. If not properly controlled, mosquitos could board ships, breed and be carried overseas. Furthermore, mosquitos on board can, in turn, spread disease to POE in other countries. However the authority has not been delegated to MO-PH or PHI-PH for implementing the Food Act or MO-PH for implementing Prevention of Mosquito Breeding Act in and near POE.

Despite the gaps in the existing legislation to prevent entry of infectious diseases and food-borne diseases, there are legal provisions related to zoonotic, chemical and radio-nuclear hazards. Animal Diseases Act (1992) (23) provides legal authority for control of import and export of animals and products in and out of the country. Part III of the Act includes powers related to of Minister to declare any port or other place as being infected with disease, power of Ports Authority to refuse entry to vessels carrying any infected or diseased animal, quarantine, protective zone etc. Animal Quarantine Units established within the POE implement the regulations. Atomic Energy Authority Act (1969) (24) has provisions control of importation, exportation, production, acquisition, treatment, storage, transport and disposal of radioactive materials. The National Environmental Act, (2000) (25) and the Chemical Weapons Conventions Act (2007) (26), address the issues related to chemicals. However, Civil Aviation Act (2010) (27), Port Authority Act (1979) (28), Disaster Management Act (2005) (29) which are important for public health security at POE do not address the role of the Ministry of Health or the Port Health Officers.

B. As per the IHR (2005) (6), a sensitive and a flexible surveillance system consisting of: (a) rapid detection, (b) risk assessment and (c) alert/notification is required. Routine surveillance data related to travelers and vessels are monitored at POE by the Port Health Office. According to the Quarantine and Disease Prevention Act rapid detection of a human case or suspect arriving at a POE are based on information, received prior to arrival, in the form of 'pratique'. Pratique is the license (Health Clearance Certificate) to enter a port in Sri Lanka on assurance from the captain that it is free from contagious disease. Additional clearance is obtained from relevant units within the POE for the imported animals, food and livestock prior to granting pratique which prevents introduction of zoonotic and food borne disease to the country. The assessment revealed that although mandatory, 'pratique' is either not requested by all arriving vessels or requested after arrival.

C. Notification of communicable diseases is a legal requirement in Sri Lanka since 1897. Some of the IHR notifiable diseases for an example: SARS, influenza caused by new sub-types are not included in the latest version of the list of notifiable diseases of Sri Lanka (2005) (22) and Director Quarantine is not designated to be notified for suspects or cases detected at POE. Notification of zoonotic events or any events likely to have significant impacts on the environment and with public health implications i.e. chemical and radio-nuclear hazards were not specified anywhere. 
D. Stakeholders operating at a POE are numerous and their roles/responsibilities and procedures are complex. As per the WHO guidelines Multidisciplinary or multi-sectoral Rapid Response Teams (RRT) should be established and be available 24/7 to rapidly respond to a PHEIC. Roles and responsibilities and a coordination mechanism of relevant stakeholders with regard to a public health emergency at a POE, were not available with the Directorate at the time of the assessment, while the respective focal points had documented all the procedures separately. Standard Operating Procedures (SOP) for management of a PHEIC by the port health staff were also not available. However, teams, involving multiple sectors had been identified and trained in the management of natural or man-made disasters within the country by the Ministry of Disaster Management and the $\mathrm{MOH}$.

E. Some essential activities for responding to a PHEIC at a POE were found to be lacking: absence of adequate facilities for isolation of affected travellers within the POE, resulting in transferring them immediately to the closest hospital, absence of designated hospitals for managing cases or suspects for each POE, absence of designated ambulances, equipment or trained personnel at the POE nor they being identified from adjacent hospitals for immediate transportation of cases or suspects to an appropriate medical facility, absence of protocols for disposal of solid and liquid waste or decontamination of baggage, cargo, areas within the vessel and the premises of the POE or disposal of human remains, absence of a location, designated and equipped for parking an affected or suspected Ship in the event of a PHEIC at Sea Port.

F. A National Preparedness and Response Plan incorporating multi-hazard approach of the IHR (2005) was not available apart from the pandemic preparedness plan developed by the Epidemiology Unit for Avian Influenza (30). A National Civil Aviation Public Health Emergency Preparedness Plan of Sri Lanka was developed as a result of the recommendations made by the assistant visit done by the international Civil Aviation organization Collaborative arrangement for the prevention and management of public health events in civil aviation (CAPSCA-AP) in 2013. A similar plan was not available for the sea ports.

G. Strengthening the skills and competencies of public health personnel is critical to the effective implementation of the IHR (2005). Simulations to respond to a Public Health Emergency and training programmes on IHR are not routinely conducted for the port health staff. With the commissioning of new International Sea ports and Air ports in the country, carder positions have been revised and approved for the POE. However, the assessment revealed that there is no job description for the Port Health staff.

A new 'border health strategy' was implemented to bridge this gap, by the $\mathrm{MOH}$ with the technical and financial assistance of the IOM. This new innovative approach was based on four main strategic areas: (a) changes to legislation, (b) preparation of 'Standard Operating Procedures and Multi-hazard Public Health Emergency Preparedness and Response Plan for the Sea Ports (available at http://srilanka.iom.int) (c) training (available at http://srilanka.iom.int) and simulations (d) e-based surveillance system.

A. Following a series of discussions through an inter-ministerial 'legislative review committee', representing Legal Officers of institutions having a stake in IHR related activities, a cabinet 
memorandum was submitted to amend the Quarantine and Prevention of Disease ordinance to and to revitalize the domestic legal framework to accommodate IHR (2005): 'events' or 'threats' were included in addition to 'contagious diseases' and 'infected persons', Director/Quarantine and MO-PH were identified as Competent Authority, international notification, partnerships and coordination with other agencies in a PHEIC and preparedness were included.

B. A manual of 'Standard Operating Procedures (SOP) for prevention, early warning and response to Public Health events at Points of Entry' was prepared subsequent to a series of Technical Working Group meetings and peer-reviews. Innovative systems changes were suggested to the routine procedures as well as to PHEIC response mechanisms, separately for Sea Ports and Airports. Strategies were built in to the SOP itself to monitor and evaluate the adherence. A close and regular supervision is suggested to ensure the total operationalization of the Quarantine and Prevention of Disease Ordinance of Sri Lanka and the IHR (2005) through the SOPs.

C. A training need assessment (31) was conducted among Port Health staff at all POE to in 2014 using a pre-tested, self-administered questionnaire which covered 34 activities under 12 areas specified in the SOP. A Training manual was prepared based on the priority training needs identified, with the aim of carrying out regular in-service training programmes and to ensure availability of a minimum number of trained personals needed to meet IHR requirements. A new monitoring and evaluation mechanism through 'quarterly reviews' for the Port Health staff at all POE were introduced at the Directorate-Quarantine to ensure the adherence to the SOPs and implementation of IHR at the POE. In addition, job descriptions were developed for the Port Health staff at all POE to enable effective implementation of IHR (2005) at POE. In collaboration with in the Disaster Preparedness and Response Unit, Ministry of Health, hands-on training on the emergency response was conducted through a desk simulation for the staff of all POE in 2015. On board Simulations in Ships and Aircrafts were planned but postponed due to the on-going Ebola epidemic at the time. A Multi-hazard Public Health Emergency Preparedness and Response Plan was developed and the roles of multi-sectoral partners were defined for the Sea Ports. A steering committee including the Ministry of Health and other relevant Ministries to provide the official structure for collaboration in case of a PHEIC needs to be established. Incorporation of IHR related hazards into the national emergency response plans of the Ministry of Disaster Management is a crucial next step.

D. A web based Border Health Information System was developed to capture data related to routine procedures as well as those related to PHEIC. The paper based record keeping at POE was converted to a real-time comprehensive e-surveillance system where data could be collected in a timely and complete manner. This data entering interphase is equipped with mechanisms to minimize errors in data entry and thereby ensure the quality of data. The data are entered using a portable web-linked devise by the MO-PH visiting Ship or the Aircraft, and are fed to the system immediately. The system sends alerts and notifications to the MO in-charge of the relevant POE and to the Director-Quarantine. The system also generates periodical reports and returns automatically and allows running of queries and analyses within the system. The system will be linked to reporting systems of to the stakeholder agencies related to implementation of IHR in the future. 


\section{Concluding remarks}

Institutionalizing IHRs as part of the routine health system requires increased awareness among policymakers, building inter-sectoral relationships, and resources. The best practices of Sri Lanka could be used to develop or to validate national strategies in other countries in the region. Enhancing public health security at POE to Sri Lanka does not stop at saving lives of people, but goes far beyond. It will be a key factor in establishing a good international image for the country, minimizing any potential travel and trade restrictions being imposed on the country, building public trust, and minimizing social and political turmoil in a potential PHEIC situation. All of this brings to a core truth. Migration health, global measures, human security and health are not simple science. It is a human problem. It is sensitive. It is intricately interlaced with human rights and human dignity. Good governance, good legislature, good implementation of laws and regulations are at the heart of all good outcomes.

\section{Acknowledgement}

I would like to acknowledge the International Organization for Migration (IOM) for the technical and logistical support.

\section{Competing interests}

None declared

\section{References}

1. World Health Organization. The world health report 2007: Global public health Security in the 21 st century - A safer future. Geneva: World Health Organization; 2007.

2. World Health Organization. Cumulative Number of Reported Probable Cases of Severe Acute Respiratory Syndrome (SARS). Geneva: World Health Organization; 2003. [cited 2015 April 08]. Available from http://www.who.int/csr/sars/country/2003 04 22/en/.

3. World Health Organization. WHO Official Records 2009: World now at the start of 2009 influenza pandemic. [cited 2015 March 10] Available from http://www.who.int/mediacentre/ news/statements/2009/h1n1_pandemic_phase 6_20090611/en/.

4. Black Death [cited 2015 February 12] Available from https://en.wikipedia.org/wiki/Black_Death.

5. World Health Organization. WHO Official Records 1969: International Health Regulations 1969, 176:22 (resolution WHA 22.46). Geneva: World Health Organization; 1969 [cited 2015 February 16] Available from http://whqlibdoc.who.int/publications/1983/9241580070.pdf.

6. World Health Organization. WHO Official Records 2005: International Health Regulations 2005 (Resolution WHA 58.3). Geneva: World Health Organization; 2005 [cited 2015 February 16] Available from http://www.who.int/ihr/IHR_2005_en.pdf.

7. Sara E, Kamradt-Scott DA, Rushton S. Disease Diplomacy: International Norms and Global Health Security. USA: Johns Hopkins University Press; 2015. 
8. Lancet Editorial. Ebola: what lessons for the International Health Regulations? Lancet vol 384 October 11, 2014 [cited 2015 March 20] Available from http://www.thelancet.com/pdfs/journals/ lancet/PIIS0140-6736(14)61697-4.pdf

9. [cited 2015 April 2] Available from www.world-nuclear.org/information-library/safety-andsecurity/safety-of-plants/fukushima-accident.aspx.

10. World Health Organization. IHR Procedures concerning public health emergencies of international concern (PHEIC). Geneva: World Health Organization [cited 2015 March 23] Available from http://www.who.int/ihr/procedures/pheic/en/.

11. World Health Organization. Statement by WHO Director-General Dr. Margaret Chan 25 April 2009: Swine influenza, Geneva: World Health Organization; 2009 [cited 2015 April 8] Available from http://www.who.int/mediacentre/news/statements/2009/h1n1_20090425/en/.

12. World Health Organization. WHO statement 8 August 2014: Statement on the 1st meeting of the IHR Emergency Committee on the 2014 Ebola outbreak in West Africa. Geneva: World Health Organization; 2014 [cited 2015 April 6] Available from http://www.who.int/mediacentre/news/ statements/2014/ebola-20140808/en/.

13. World Health Organization. WHO statement 2015: meeting of the International Health Regulations Emergency Committee concerning the international spread of wild poliovirus. Geneva: World Health Organization; 2015 [cited 2015 April 18] Available from http://www.who.int/mediacentre/ news/statements/2014/polio-20140505/en/.

14. Failures of fully operationalizing the concept of global governance of disease through IHR [cited 2015 April 20] Available from http://www.ghgj.org/Katz\%20and\%20Fischer_The\%20 Revised\%20International\%20Health\%20Regulations.pdf.

15. Parliament of the Democratic Republic of Sri Lanka. Quarantine and Prevention of Diseases 'Act No. 12, 1952. Sri Lanka: Parliament of the Democratic Republic of Sri Lanka; 1952.

16. Premaratne R, Ortega L, Navaratnasinghe J, Mendis KN. Malaria elimination from Sri Lanka: What it would take to reach the goal. WHO South-East Asia J Public Health. 2014; 3:85-9.

Wickramage K, Peiris S, Agampodi, SB "Don’t Forget the Migrants": Exploring Preparedness and Response Strategies to Combat the Potential Spread of MERS-Co V Virus through Migrant Workers in Sri Lanka; F1000Research, Vol.2-163, 2013.

17. World Health Organization. International Health Regulations 2005-IHR core capacity monitoring framework: Checklist and Indicators for Monitoring Progress in the Development of IHR Core Capacities in States Parties 2013, Geneva: World Health Organization; 2015.

18. Parliament of the Democratic Republic of Sri Lanka. Food Act No. 20, 1991. Sri Lanka: Parliament of the Democratic Republic of Sri Lanka; 1991.

19. Parliament of the Democratic Republic of Sri Lanka. Prevention of Mosquito Breeding Act No.11, 2007. Sri Lanka: Parliament of the Democratic Republic of Sri Lanka; 2007. 
20. Ministry of Health. SARS regulations 2003. Sri Lanka. Epidemiology Unit, Ministry of Health; 2003.

21. Ministry of Health. Surveillance case definitions for notifiable diseases in Sri Lanka. Sri Lanka: Epidemiology Unit, Ministry of Health; 2005.

22. Parliament of the Democratic Republic of Sri Lanka. Animal Diseases Act, No. 59 of 1992. Sri Lanka: Parliament of the Democratic Republic of Sri Lanka; 1992.

23. Parliament of the Democratic Republic of Sri Lanka. Sri Lanka Atomic Energy Act, No. 40. Sri Lanka: Parliament of the Democratic Republic of Sri Lanka; 2014.

24. Parliament of the Democratic Republic of Sri Lanka. National Environmental Act, No. 53. Sri Lanka: Parliament of the Democratic Republic of Sri Lanka; 2000.

25. Parliament of the Democratic Republic of Sri Lanka. Chemical Weapons Convention Act, No. 58.. Sri Lanka: Parliament of the Democratic Republic of Sri Lanka; 2007.

26. Parliament of the Democratic Republic of Sri Lanka. Civil Aviation Act No.14. Sri Lanka: Parliament of the Democratic Republic of Sri Lanka; 2010.

27. Parliament of the Democratic Republic of Sri Lanka. Port Authority Act No. 51. Sri Lanka: Parliament of the Democratic Republic of Sri Lanka; 1979.

28. Parliament of the Democratic Republic of Sri Lanka. Disaster Management Act No. 13. Sri Lanka: Parliament of the Democratic Republic of Sri Lanka; 2005.

29. Ministry of Health. National Influenza Pandemic Preparedness Plan, 2012. Sri Lanka: Epidemiology Unit, Ministry of Health; 2012.

30. Hicks, C, Hennessy, D and Barwell, F. The development of a psychometrically valid training needs analysis instrument for use with primary health care teams. Health Services Management Research 9 1996; 262 -272. 